\title{
Rotavirus Vaccine: A Promise for the Future
}

Rotaviruses-non-enveloped, double-stranded RNA viruses-infect both humans and animals and are distributed worldwide. In humans, rotavirus causes diarrhoea of varying severity ranging from mild to severe. Symptoms, such as diarrhoea, vomiting, and fever, begin after an incubation period of 2-3 days and persist, on average, for six days (1). Rotavirus is the leading cause of severe diarrhoea in infants and young children, accounting for $45 \%$ of severe diarrhoeal disease in both developed and developing countries $(2,3)$, responsible for $\sim 5 \%$ of all deaths and $16 \%$ of potentially vaccine-preventable deaths among children globally $(2,4)$. Rotaviruses are associated with $55 \%$ of all diarrhoea-related hospitalizations among children aged less than five years as revealed in the reports of the Asian Rotavirus Surveillance Network (5). Virtually, all children throughout the world are infected with rotavirus by the time they are 3-5 years old, regardless of the socioeconomic status or environmental conditions $(2,6)$.

The World Health Organization has recently estimated that 611,000 (range 454,000-705,000) deaths due to rotavirus occur in children aged less than five years, accounting for approximately 20$25 \%$ of all deaths due to diarrhoeal disease (7). Of the deaths due to rotavirus occurring worldwide, it is estimated that approximately 145,000 deaths occur in sub-Saharan Africa and approximately 200,000 deaths occur in Asia (8-10).

Studies have shown that rotavirus-associated disease occurs round the year in tropical climates with no consistent seasonal variation, although there may be more peaks in the dry, cool months, or winter months (11). Serotype G1, G2, G3, and G4 are responsible for $88 \%$ of gastroenteritis due to rotavirus, worldwide (12). These serotypes also account for over $80 \%$ of strains in Africa and over 90\% of strains in Asia. Other G serotypes that have

Correspondence and reprint requests should be addressed to:

Dr. K. Zaman

Scientist and Epidemiologist

Child Health Unit

Public Health Sciences Division

ICDDR,B

GPO Box 128, Dhaka 1000, Bangladesh

Email: kzaman@icddrb.org

Fax: 880-2-8826050 become more common over the last decade include G9 (globally) and G8 (in Africa). Unusual G and P type combinations have been identified in Africa with an increasing frequency (13).

Safe and effective rotavirus vaccines are needed to reduce the enormous public-health burden associated with illness due to rotavirus, especially in developing countries (14). The large global burden of healthcare due to rotavirus-associated disease in both developed and developing countries prompted the development of rotavirus vaccines. Prevention by vaccination is considered to be critical for effective control of infection due to rotavirus since it cannot be prevented with improvements in water and sanitation (11), and only non-specific symptomatic therapies are available. Various approaches to the development of rotavirus vaccines have been undertaken, with live-attenuated oral vaccines receiving the most attention.

The first licensed rotavirus vaccine-RotaShield-a tetravalent rhesus rotavirus vaccine was manufactured by Wyeth-Lederle and was licensed in the USA in 1998, and marketing authorization was granted for Europe in 1999 but was withdrawn from the market in 1999 due to an increased risk of intussusception shortly after its administration $(15,16)$. Unanticipated adverse events (intussusception) experienced with the RotaSheild vaccine have accelerated efforts to develop and evaluate alternative vaccine candidates so that a safe and effective public-health tool would become available. Two new rotavirus vaccines-Rotarix by GSK and Rotateq by Merckhave been developed. Both the vaccines were tested in both industrialized and middle-income countries among more than 60,000 infants which demonstrated its safety and efficacy. The vaccine had an efficacy of 85-98\% against severe rotavirus-associated disease requiring hospitalization and reduced all-cause hospitalizations by $42-59 \%$, preventing nearly all hospitalizations for rotavirus $(17,18)$. Both the vaccines did not interfere with the immunogenicity when co-administered with other EPI vaccines, including polio (19-21). The vaccines were not associated with an increased risk of intussusception.

This issue of the Journal includes an article by Constenla et al. who evaluated the cost-effectiveness of a national rotavirus-vaccination progrmme in Brazilian children (22). The authors developed a model 
to estimate the disease outcomes and healthcare costs associated with diarrhoea due to rotavirus in a hypothetical annual birth-cohort of children for a five-year period. It has been estimated that rotavirus vaccination in Brazil would prevent more than three-fourths of outpatient visits, hospitalizations, and deaths. The authors conclude that the rotavirus-vaccination programme would be cost-effective and would provide an effective opportunity for improving child health in Brazil.

Further analyses were done to estimate the economic burden and cost-effectiveness of rotavirus vaccination in Asia. The universal vaccination programme in Asia would also reduce a substantial proportion of the burden of rotavirus-associated disease and related healthcare costs in Asia (23). They estimated reduction of 109,000 deaths (64\%), 1.4 million hospitalizations (74\%), 7.7 million outpatient visits (57\%), and US\$ 139 million (73\%) in healthcare costs.

Both the vaccines-Rotarix and Rotateq-were approved by the FDA, and the vaccines have been licensed in many countries. Different countries have already adopted the rotavirus vaccine in their routine EPI programme. Post-licensure monitoring of the burden of rotavirus-associated disease, safety of vaccine, and determination of circulating rotavirus strains are needed. However, several challenges remain before the widespread use of rotavirus vaccines in developing countries. These include pricerelated issues, awareness of diseases due to rotavirus, and acceptance of the vaccine $(24,25)$.

There are concerns about the efficacy of rotavirus vaccine in developing countries since live oral enteric vaccines (polio, rotavirus) have been shown to be less immunogenic compared to developed countries $(26,27$; Steele AD. Personal communication, 2008). Further research would be helpful to determine the safety and efficacy of the vaccines, particularly among children in developing countries with a high prevalence of malnutrition, widespread circulation of intestinal micro-organisms, and accompanying diseases, such as malaria and HIV. The demonstration of immune responses in presence of high maternal antibodies and breastfeeding at the time of vaccination is important. The results of the ongoing rotavirus efficacy trials in Asia (Bangladesh and Viet Nam) and Africa (Kenya, Ghana, and Mali) would provide information whether the vaccine works well in developing countries. The rotavirus-effectiveness study which has just been started in Bangladesh will provide ex- perience with the vaccine in a 'real-world' setting, and lessons will be learnt on vaccine delivery in the villages of Bangladesh. This would be helpful for the health ministry to decide to include the vaccine in its EPI programme for a rapid scale-up.

The inclusion of rotavirus vaccine in the routine childhood-immunization programme in developing countries will help achieve the Millennium Development Goal of reducing childhood mortality through prevention of deaths due to rotavirus-associated diseases (28).

\section{REFERENCES}

1. Velázquez FR, Matson DO, Calva JJ, Guerrero L, Morrow AL, Carter-Campbell S et al. Rotavirus infections in infants as protection against subsequent infections. N Engl J Med 1996;335:1022-8.

2. Parashar UD, Hummelman EG, Bresee JS, Miller MA, Glass RI. Global illness and deaths caused by rotavirus disease in children. Emerg Infect Dis 2003;9:56572.

3. Ciarlet M, Estes MK. Rotaviruses: basic biology, epidemiology and methodologies. In: Bitton G, editor. Encyclopedia of environmental microbiology. New York, NY: Wiley, 2002:2753-73.

4. Vaccine preventable deaths and the global immunization vision and strategy, 2006-2015. MMWR 2006/55:511-5.

5. Bresee JS, Fang ZY, Wang B, Nelson EA, Tam J, Soenarto $\mathrm{Y}$ et al. Rotavirus surveillance in Asia: first report from "Asian Rotavirus Surveillance Network". Emerg Infect Dis 2003;10:95-8.

6. Kapikian AZ, Hoshino Y, Chanock RM. Rotaviruses. In: Knipe DM, Howley PM, editors. Fields virology. $4^{\text {th }}$ ed. Philadelphia, PA: Lippincott-Raven, 2001:1787833.

7. Parashar UD, Gibson C, Bresee JS, Glass RI. Rotavirus and severe childhood diarrhea. Emerg Infect Dis 2006;12:304-6.

8. Bresee JS, Hummelman E, Nelson EA, Glass RI. Rotavirus in Asia: the value of surveillance for informing decisions about the introduction of new vaccines. $J$ Infect Dis 2005;192:S1-5.

9. Lanata CF, Black RE, del Aguila R, Gil A, Verastegui H, Gerna G et al. Protection of Peruvian children against rotavirus diarrhea of specific serotypes by one, two, or three doses of the RIT 4237 attenuated bovine rotavirus vaccine. J Infect Dis 1989;159:452-9.

10. Mølbak K, Fischer TH, Mikkelsen CS. The estimation of mortality due to rotavirus infections in sub-Saharan Africa. Vaccine 2000;19:393-5. 
11. Bresee JS, Glass RI, Ivanoff B, Gentsch J. Current status of future priorities for rotavirus vaccine development, evaluation and implementation in developing countries. Vaccine 1999;17:2207-22.

12. Santos N, Hoshino Y. Global distribution of rotavirus serotypes/genotypes and its implication for the development and implementation of an effective rotavirus vaccine. Rev Med Virol 2005;15:29-56.

13. Steele AD, Ivanoff B. Rotavirus strains circulating in Africa during 1996-1999: emergence of G9 strains and $\mathrm{P}[6]$ strains: progress on enteric vaccines. Vaccine 2003;21:361-7.

14. Miller MA, McCann L. Policy analysis of the use of hepatitis B, Haemophilus influenzae type b-, Streptococcus pneumonia-conjugate and rotavirus vaccines in national immunization schedule. Health Econ 2000;9:19-35.

15. Centers for Disease Control and Prevention. Withdrawal of rotavirus vaccine recommendation. MMWR 1999;48:1007.

16. Murphy TV, Gargiullo PM, Masssoudi MS, Nelson DB, Jumaan AO, Okoro CA et al. Intussusception among infants given an oral rotavirus vaccine. $N$ Engl J Med 2001;344:564-72.

17. Ruiz-Palacios GM, Pérez-Schael I, Velázquez FR, Abate $\mathrm{H}$, Breuer T, Clemens SC et al. Safety and efficacy of an attenuated vaccine against severe rotavirus gastroenteritis. N Eng J Med 2006;354:11-22.

18. Vesikari T, Matson DO, Dennehy P, Van Damme P, Santosham M, Rodriguez Z et al. Safety and efficacy of a pentavalent human-bovine (WC3) reassortant rotavirus vaccine. $N$ Engl J Med 2006;354:23-33.

19. Steele AD, De Vos B, Tumbo J, Reynders J, Scholtz F, Bos $\mathrm{P}$ et al. Co-administration study in South African infants of a live-attenuated oral human rotavirus vaccine (RIX4414) and poliovirus vaccines. Vaccine 2008 (in press).

20. Ciarlet M, Sani-Grosso R, Yuan G, Liu GF, Heaton PM, Gottesdiener KM et al. Concomitant use of the oral pentavalent human-bovine reassortant rotavirus vaccine and oral poliovirus vaccine. Pediatr Infect Dis J 2008;27:874-80.
21. Zaman K, Sack DA, Yunus M, Arifeen SE, Bouckenooghe A, Delem A et al.; Bangladesh Rotavirus Vaccine Team. Immunogenicity of an oral polio vaccine is unaffected when co-administered with a human rotavirus vaccine in Bangladeshi children (abstract). In: Book of abstract of the $5^{\text {th }}$ World Congress of the World Society for Paediatric Infectious Disease, Bangkok, November 15-18, 2007. Geneva: World Society for Paediatric Infectious Diseases, 2007:244.

22. Constenla DO, Linhares AC, Rheingans RD, Antil LR, Waldman EA, da Silva LJ. Economic impact of a rotavirus vaccine in Brazil. J Health Popul Nutr 2008;26:388-96.

23. Podewls LJ, Antil L, Hummelman E, Bresee J, Parashar UD, Rheingans R. Projected cost-effectivness of rotavirus vaccination for children in Asia. J Infect Dis 2005;192:S133-45.

24. Glass RI, Parashar UD, Bresee JS, Turcois R, Fischer TK, Widdowson MA et al. Rotavirus vaccines: current prospects and future challenges. Lancet 2006;368:32332.

25. Parashar UD, Glass RI. Public health. Progress towards rotavirus vaccine. Science 2006;312:851-2.

26. John TJ, Jayabal P. Oral polio vaccination of children in the tropics. I. The poor seroconversion rates and the absence of viral interference. Am J Epidemiol 1972;96:263-9.

27. De Vos B, Vesikari T, Linhares AC, Salinas B, PérezSchael I, Ruiz-Palacios GM et al. A rotavirus vaccine for prophylaxis of infants against rotavirus gastroenteritis. Pediatr Infect Dis J 2004;23:S179-82.

28. Glass RI, Parasher UD. The promise of new rotavirus vaccine. N Engl J Med 2006;354:75-7.

K. Zaman

Scientist and Epidemiologist

Child Health Unit

Public Health Sciences Division

ICDDR,B

GPO Box 128, Dhaka 1000

Bangladesh 